\title{
Spectrofluorometric Determination of Kynurenic Acid with Horseradish Peroxidase in the Presence of Hydrogen Peroxide
}

\author{
Junichi Odo, ${ }^{\dagger}$ Tomomi FunaI, and Akihito HiraI \\ Department of Biological Chemistry, Faculty of Science, Okayama University of Science, \\ 1-1 Ridai-cho, Okayama 700-0005, Japan
}

\begin{abstract}
The catalytic activity of horseradish peroxidase (HRP) in the presence of hydrogen peroxide has been investigated for the fluorescent derivatization of kynurenic acid under conditions with no exposure to light. Non-fluorescent kynurenic acid was converted into a fluorescent compound (Ex: $367 \mathrm{~nm}, \mathrm{Em}: 470 \mathrm{~nm}$ ) with HRP in the presence of hydrogen peroxide, and the optimum conditions of this fluorescent derivatization were investigated. Moreover, this fluorescent derivatization was developed for a spectrofluorometric determination of trace amounts of kynurenic acid by measuring the fluorescence intensity of the fluorescent compound. The calibration curve obtained was linear from 1.0 to $10.0 \mathrm{nmol}$ of kynurenic acid in a $1.0 \mathrm{~mL}$ sample solution. The relative standard deviation at $5.0 \mathrm{nmol}$ of kynurenic acid was $5.71 \%(n=5)$. By adjusting the bandwidths for both the excitation and emission to $15 \mathrm{~nm}$, the calibration curve was also linear in the range between 0.1 to $1.0 \mathrm{nmol}$ of kynurenic acid in a $1.0 \mathrm{~mL}$ sample solution. This method was applied to the fluorometric determination of trace amounts of kynurenic acid in the control sera.
\end{abstract}

(Received November 13, 2006; Accepted January 23, 2007; Published March 10, 2007)

\section{Introduction}

Horseradish peroxidase (HRP) is well known to catalyze the following reaction (1), in which substrates $\left(\mathrm{AH}_{2}\right)$ are oxidized to a corresponding reaction product (A) by the catalytic activity of $\mathrm{HRP}$ in the presence of $\mathrm{H}_{2} \mathrm{O}_{2}$. In general, reaction (1) is routinely applied to the photometric or fluorometric determination of trace amounts of $\mathrm{H}_{2} \mathrm{O}_{2}$ in various fields of chemistry, such as clinical, environmental and food chemistry. ${ }^{1-4}$

$$
\mathrm{AH}_{2}+\mathrm{H}_{2} \mathrm{O}_{2} \stackrel{\mathrm{HRP}}{\longrightarrow} \mathrm{A}+2 \mathrm{H}_{2} \mathrm{O}
$$

For the fluorometric determination of trace amounts of $\mathrm{H}_{2} \mathrm{O}_{2}$, some non-fluorescent fluorochromogen such as 3- $(p-$ hydroxyphenyl)propionic acid and homovanillic acid as $\mathrm{AH}_{2}$ were selected, and the fluorescence intensity of the corresponding fluorescent compounds produced through reaction (1) was measured. ${ }^{5,6}$ In these cases, reaction (1) proceeded quantitatively in the presence of excess $\mathrm{AH}_{2}$ to trace amounts of $\mathrm{H}_{2} \mathrm{O}_{2}$. Conversely, if reaction (1) will proceed quantitatively, even in the presence of excess $\mathrm{H}_{2} \mathrm{O}_{2}$ to trace amounts of $\mathrm{AH}_{2}, \mathrm{AH}_{2}$ will be determinable by measuring the reaction product (A). Accordingly, for developing a fluorometric determination of trace amounts of non-fluorescent $\mathrm{AH}_{2}$, we tried to apply reaction (1), in which a non-fluorescent substrate could be converted into a fluorescent product by the catalytic activity of HRP in the presence of excess $\mathrm{H}_{2} \mathrm{O}_{2}$.

Kynurenic acid (KA) is non-fluorescent, one of the metabolites of tryptophan, and is of great interest in terms of its connection with various diseases, such as diabetes and vitamin

$\dagger$ To whom correspondence should be addressed.

E-mail: odo@dbc.ous.ac.jp
$\mathrm{B}_{6}$ deficiency. ${ }^{7-10}$ Therefore, it is very important to measure the concentration of KA in vital fluids for determining the proper diagnosis of such diseases. So far, for measuring trace amounts of KA in vital fluids, various methods have been demonstrated regarding photometric and fluorometric determinations, and so on. ${ }^{11-17}$ In particular, Watanabe et al. have demonstrated fluorometric methods that involve an enhancement of the fluorescence intensity of KA by adding a zinc acetate reagent, or using the conversion of KA into a fluorescent compound by ultraviolet irradiation in the presence of $\mathrm{H}_{2} \mathrm{O}_{2} \cdot{ }^{14,15}$ These methods have been applied to the determination of KA in vital fluids, such as plasma, urine and cerebrospinal fluid. However, some disadvantages still remain regarding the irradiation time of ultraviolet light and a waste containing zinc ion.

Accordingly, in an attempt to develop a new method for fluorometric determination of trace amounts of KA, we selected non-fluorescent $\mathrm{KA}$ as the substrate, and investigated whether KA will be converted into a fluorescent compound during reaction (1) and moreover KA can be determined by measuring the fluorescence intensity of the reaction product. To the best of our knowledge, no fluorometric method using the catalytic activity of HRP in the presence of $\mathrm{H}_{2} \mathrm{O}_{2}$ has been demonstrated for the determination of trace amounts of KA.

\section{Experimental}

\section{Reagents and apparatus}

KA was purchased from Seikagaku Kogyo Co. and used without further purification. HRP, and control serum I and II were purchased from Wako Pure Chemical Industries Co. All other chemicals were of analytical or reagent grade, and used without further purification.

The fluorescence spectra and fluorescence intensities were recorded on a Shimadzu RF-5300 spectrofluorometer with a 
Table 1 Fluorescent derivatization of KA under various conditions

\begin{tabular}{ccccc}
\hline $\begin{array}{c}\text { Sample solution } \\
\text { total: } 5.0 \mathrm{~mL} \text { ) }\end{array}$ & $\begin{array}{c}\mathrm{KA} / \\
\mathrm{nmol}\end{array}$ & $\begin{array}{c}\mathrm{HRP} / \\
\text { units }\end{array}$ & $\begin{array}{c}\mathrm{H}_{2} \mathrm{O}_{2} / \\
\mu \mathrm{mol}\end{array}$ & $\begin{array}{c}\text { Fluorescence } \\
\text { intensity } / \mathrm{a} . \mathrm{u} .\end{array}$ \\
\hline Solution (A) & 5.0 & 2.0 & 50 & 400 \\
Solution (B) & 5.0 & 2.0 & 0 & $\sim 0$ \\
Solution (C) & 5.0 & 0 & 50 & $\sim 0$ \\
Solution (D) & 5.0 & 0 & 0 & $\sim 0$ \\
\hline
\end{tabular}

a. The intensity was measured at excitation and emission wavelengths of 367 and $470 \mathrm{~nm}$, respectively. All solutions were incubated for 30 min in a $\mathrm{pH} 6.0$ phosphate buffer at room temperature without exposure to light.

quartz cell $(1 \mathrm{~cm} \times 1 \mathrm{~cm}$ cross-section) equipped with a xenon lamp and a dual monochromator. For all experiments in this study, the bandwidths for both excitation and emission were set at $10 \mathrm{~nm}$, unless otherwise noted.

\section{HRP method for determination of $K A$}

A HRP solution $\left(1.0 \mathrm{~mL}, 2.0 \mathrm{U} \mathrm{mL}^{-1}\right)$ was added to a mixture containing a sample solution (1.0 mL, $1.0-10.0 \mathrm{nmol}$ of KA), a $50 \mathrm{mM} \mathrm{H}_{2} \mathrm{O}_{2}$ solution $(1.0 \mathrm{~mL})$ and a $1 / 15 \mathrm{M}$ phosphate buffer solution $(3.0 \mathrm{~mL}, \mathrm{pH} 6.0)$; the mixture was incubated at $35^{\circ} \mathrm{C}$ for $30 \mathrm{~min}$ without exposure to light. The fluorescence intensity of the mixture solution was measured at excitation and emission wavelengths of 367 and $470 \mathrm{~nm}$, respectively. The fluorescence intensity of a reagent blank solution was similarly measured under the same conditions.

\section{Removal of serum protein from control serum I and II}

A mixture of serum $(1.0 \mathrm{~mL})$ and $0.6 \mathrm{M} \mathrm{HClO}_{4}(4.0 \mathrm{~mL})$ was adequately stirred, and then allowed to stand for $10 \mathrm{~min}$ in ice. After the solution was centrifuged at $3000 \mathrm{rpm}$ for $10 \mathrm{~min}$, the supernatant $(2.5 \mathrm{~mL})$ of the reaction mixture was neutralized with $2 \mathrm{~N} \mathrm{NaOH}$, and its total volume was adjusted to $5.0 \mathrm{~mL}$ with a 1/15 M phosphate buffer ( $\mathrm{pH} 6.0)$. One milliliter of this solution was used as a sample solution for the HRP method.

The buffer solutions used were $1 / 15 \mathrm{M} \mathrm{KH}_{2} \mathrm{PO}_{4}-1 / 15 \mathrm{M}$ $\mathrm{Na}_{2} \mathrm{HPO}_{4}$ for $\mathrm{pH} 5.0-8.0$. Buffer solutions used for $\mathrm{pH} 6.0$ were $\left(1 / 25 \mathrm{M} \mathrm{H}_{3} \mathrm{PO}_{4}, 1 / 25 \mathrm{M} \mathrm{CH}_{3} \mathrm{COOH}, 1 / 25 \mathrm{M} \mathrm{H}_{3} \mathrm{BO}_{3}\right)-0.2$ $\mathrm{M} \mathrm{NaOH}, 0.1 \mathrm{M} \mathrm{NH}_{4} \mathrm{Cl}-0.1 \mathrm{M} \mathrm{NH}_{4} \mathrm{OH},\left(0.2 \mathrm{M} \mathrm{H}_{3} \mathrm{BO}_{3}, 0.05 \mathrm{M}\right.$ $\mathrm{NaCl})-0.05 \mathrm{M} \mathrm{Na}_{2} \mathrm{~B}_{4} \mathrm{O}_{7}$, and 0.1 $\mathrm{M} \mathrm{HCl}-0.05 \mathrm{M} \mathrm{Na}_{2} \mathrm{~B}_{4} \mathrm{O}_{7}$.

\section{Results and Discussion}

\section{Fluorescent derivatization of $K A$ with $H R P$}

Mawatari et al. have demonstrated that KA, a non-fluorescent compound, was converted into a fluorescent compound by a photochemical reaction through ultraviolet irradiation in the presence of $\mathrm{H}_{2} \mathrm{O}_{2}{ }^{15}$ This indicates that $\mathrm{KA}$ is very sensitive to the irradiation of ultraviolet light, and is easily converted into a fluorescent compound by a photochemical reaction. Accordingly, in this study, all experiments were carried out under the condition of no exposure to light in order to avoid this photochemical reaction of KA with $\mathrm{H}_{2} \mathrm{O}_{2}$.

As shown in Table 1, the fluorescence intensities of reaction solutions containing KA under various conditions were measured for investigating whether KA will be converted into a fluorescent compound with $\mathrm{HRP}$ in the presence of $\mathrm{H}_{2} \mathrm{O}_{2}$ or not. All solutions were incubated for $30 \mathrm{~min}$ in a $\mathrm{pH} 6.0$ phosphate buffer at room temperature, and their fluorescence intensities

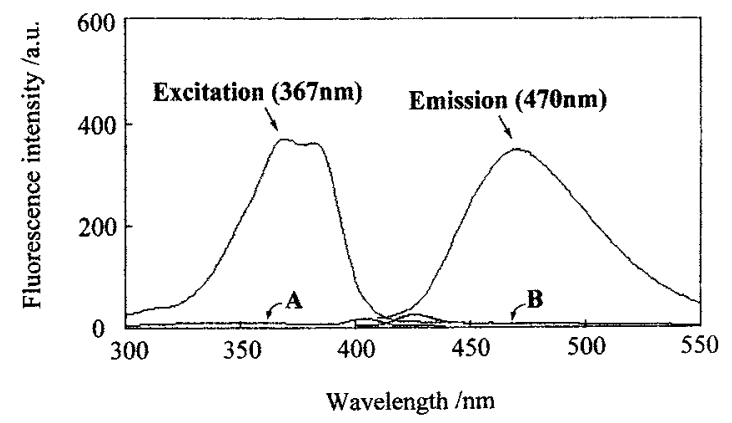

Fig. 1 Excitation and emission spectra of a fluorescent compound produced with $\mathrm{HRP}$ in the presence of $\mathrm{H}_{2} \mathrm{O}_{2}$ without exposure to light. After a mixture containing a KA solution $(1.0 \mathrm{~mL}, 5.0 \mu \mathrm{mol})$, a $50 \mathrm{mM} \mathrm{H} \mathrm{O}_{2}$ solution $(1.0 \mathrm{~mL}), 2.0 \mathrm{U} \mathrm{mL}^{-1} \mathrm{HRP}$ solution $(1.0 \mathrm{~mL})$ and $1 / 15 \mathrm{M}$ phosphate buffer solution (3.0 mL, $\mathrm{pH}$ 6.0) was incubated at $35^{\circ} \mathrm{C}$ for $30 \mathrm{~min}$ without exposure to light, the fluorescence intensity of the mixture was measured. The spectra (A and B) show the respective blank fluorescence.

were measured at excitation and emission wavelengths of 367 and $470 \mathrm{~nm}$, respectively. As shown in Table 1, solution (D) containing only KA showed no fluorescence. Only solution (A) containing both $\mathrm{HRP}$ and $\mathrm{H}_{2} \mathrm{O}_{2}$ showed strong fluorescence, whereas solutions (B) and (C) without HRP or $\mathrm{H}_{2} \mathrm{O}_{2}$ showed almost no fluorescence. It is apparent that KA was converted into the fluorescent compound only in the presence of both HRP and $\mathrm{H}_{2} \mathrm{O}_{2}$, even without exposure to light. Figure 1 shows the excitation and emission spectra of solution (A). It is clear that KA was converted into a fluorescent compound (Ex: $367 \mathrm{~nm}$, Em: $470 \mathrm{~nm}$ ) by the catalytic activity of HRP in the presence of $\mathrm{H}_{2} \mathrm{O}_{2}$, even without exposure to light, and is capable of being determined fluorometrically by measuring the fluorescence intensity of the reaction product during reaction (1).

As described previously, Mawatari et al. ${ }^{15}$ has shown that KA was converted into a fluorescent compound by a photochemical reaction through ultraviolet irradiation in the presence of $\mathrm{H}_{2} \mathrm{O}_{2}$. The excitation and emission wavelengths of this fluorescent compound are 370 and $465 \mathrm{~nm}$, and are almost the same as that of a fluorescent product in this study, respectively. However, it is not clear whether the fluorescent compound described in the literature $^{15}$ is quite same as that produced in this study or not, because no mention is made of its structure of the fluorescent compound in the literature. ${ }^{15}$ In reaction (1), where HRP catalyzes, it is well known that the substrate acts as a proton donor to be oxidized into the reaction product with $\mathrm{H}_{2} \mathrm{O}_{2}$. Generally, substrates are known to act not only as a two-proton donor $\left(\mathrm{AH}_{2}\right)$ but also as a mono-proton donor $(\mathrm{AH})$ in reaction (1). For example, non-fluorescent 3-(p-hydroxyphenyl)propionic acid and homovanillic acid as substrates have been shown to act as a mono-proton donor to be oxidized into the corresponding fluorescent dimer, according to reaction (1). ${ }^{18,19}$ In analogy with 3-(p-hydroxyphenyl)propionic acid and homovanillic acid, KA may be oxidized with $\mathrm{H}_{2} \mathrm{O}_{2}$ and condensed to produce a fluorescent dimer, although the structure of the reaction product in this study is still not clear. Because HRP is not always so specific in its choice of substrates, KA may participate as a mono-proton donor in reaction (1) to be oxidized into a fluorescent dimer.

Investigation of optimum conditions for the fluorescent derivatization of $K A$ with $H R P$

In order to establish the optimum conditions for the 
Table 2 Effects of the buffer on the fluorescent derivatization of KA with $\mathrm{HRP}$ at $\mathrm{pH} 6.0$ in the presence of $\mathrm{H}_{2} \mathrm{O}_{2}$ without exposure to light

\begin{tabular}{|c|c|}
\hline Buffer (pH 6.0) & $\begin{array}{l}\text { Fluorescence } \\
\text { intensity/a.u. }\end{array}$ \\
\hline $1 / 15 \mathrm{M} \mathrm{KH}_{2} \mathrm{PO}_{4}-1 / 15 \mathrm{M} \mathrm{Na}_{2} \mathrm{HPO}_{4}$ & 400 \\
\hline $0.1 \mathrm{M} \mathrm{NH}_{4} \mathrm{Cl}-0.1 \mathrm{M} \mathrm{NH}_{4} \mathrm{OH}$ & 295 \\
\hline $0.05 \mathrm{M} \mathrm{Na}_{2} \mathrm{~B}_{4} \mathrm{O}_{7}-\left(0.2 \mathrm{M} \mathrm{H}_{3} \mathrm{BO}_{3}, 0.05 \mathrm{M} \mathrm{NaCl}\right)$ & 250 \\
\hline $1 / 25 \mathrm{M}\left(\mathrm{H}_{3} \mathrm{PO}_{4}, \mathrm{CH}_{3} \mathrm{COOH}, \mathrm{H}_{3} \mathrm{BO}_{3}\right)-0.2 \mathrm{M} \mathrm{NaOH}$ & 110 \\
\hline $0.05 \mathrm{M} \mathrm{Na}_{2} \mathrm{~B}_{4} \mathrm{O}_{7}-0.1 \mathrm{M} \mathrm{HCl}$ & 100 \\
\hline
\end{tabular}

fluorescent derivatization of KA with HRP in the presence of $\mathrm{H}_{2} \mathrm{O}_{2}$, experiments by using the HRP method for determining KA with $5.0 \mathrm{nmol}$ of KA were carried out without exposure to light.

\section{Effects of the $\mathrm{pH}$ and buffers}

The catalytic activity of HRP for the conversion of KA into a fluorescent compound was investigated in phosphate buffer solutions between $\mathrm{pH} 5$ and 8 . Figure 2 shows the fluorescence intensities of solutions obtained in each buffer solution. As shown in Fig. 2, HRP exhibited high levels of catalytic activity in a buffer solution of $\mathrm{pH}$ 6. Moreover, HRP exhibited the highest activity in a phosphate buffer solution among various buffer solutions of $\mathrm{pH}$ 6, as shown in Table 2. These results are reasonable because the optimum $\mathrm{pH}$ of HRP is about $\mathrm{pH} 6$. Accordingly, a phosphate buffer solution of $\mathrm{pH} 6.0$ was selected as the optimum $\mathrm{pH}$ and a buffer for the fluorescent derivatization of KA.

\section{Effects of the concentration of $\mathrm{H}_{2} \mathrm{O}_{2}$ and $\mathrm{HRP}$}

Both concentrations of $\mathrm{H}_{2} \mathrm{O}_{2}$ and $\mathrm{HRP}$ affected the fluorescent derivatization of KA. The effect of the concentration of $\mathrm{H}_{2} \mathrm{O}_{2}$ for the fluorescent derivatization of KA was investigated in the range of 10 to $60 \mathrm{mM} \mathrm{H}_{2} \mathrm{O}_{2}$. Although an increase of the fluorescent intensity was observed with increasing the concentration of $\mathrm{H}_{2} \mathrm{O}_{2}$, the fluorescent intensities became almost constant, and maximum over $50 \mathrm{mM}$ of $\mathrm{H}_{2} \mathrm{O}_{2}$. The fluorescence intensities were almost constant and maximum between 2.0 and $5.0 \mathrm{U} \mathrm{mL}^{-1}$ of HRP. Thus, the concentrations of $\mathrm{H}_{2} \mathrm{O}_{2}$ and HRP were selected as $50 \mathrm{mM}$ and $2.0 \mathrm{U} \mathrm{mL}^{-1}$, respectively.

\section{Effects of the incubation time and the incubation temperature}

The effects of the incubation time and the incubation temperature for the fluorescent derivatization of $\mathrm{KA}$ were investigated in the range of 10 to $60 \mathrm{~min}$ and 25 and $45^{\circ} \mathrm{C}$, respectively. The fluorescence intensities became constant and maximum after $30 \mathrm{~min}$ of incubation time. Thus, the incubation time was chosen to be $30 \mathrm{~min}$. The fluorescence intensities became maximum at $35^{\circ} \mathrm{C}$ among 25 and $45^{\circ} \mathrm{C}$ of the incubation temperature. As the incubation temperature, $35^{\circ} \mathrm{C}$ was selected.

\section{Fluorometric determination of $K A$ and the calibration curve}

Based on the optimum conditions described above for the fluorescent derivatization of KA with HRP in the presence of $\mathrm{H}_{2} \mathrm{O}_{2}$, the HRP method for the fluorometric determination of KA was established. Under these optimum conditions, a linear calibration curve was obtained between 1.0 and $10.0 \mathrm{nmol}$ of $\mathrm{KA}$ in a $1.0 \mathrm{~mL}$ sample solution, as shown in Fig. 3. The correlation coefficient and the relative standard deviation $(n=$ 5) were 0.9955 and $5.71 \%$ for $5.0 \mathrm{nmol}$ of $\mathrm{KA}$ in a $1.0 \mathrm{~mL}$ sample solution, respectively. By adjusting the bandwidths for both excitation and emission to $15 \mathrm{~nm}$, the calibration curve was

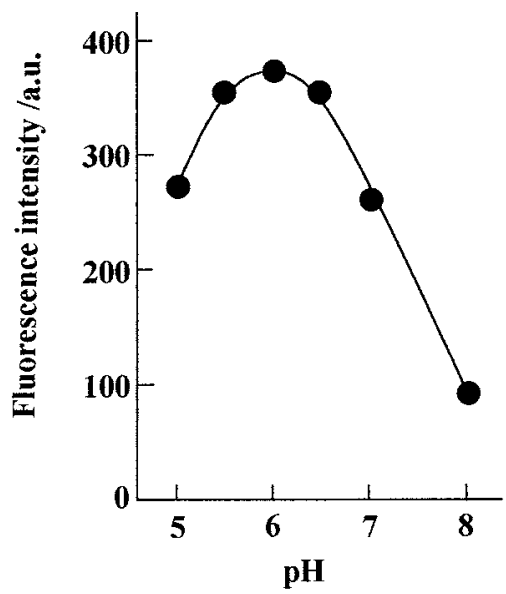

Fig. 2 Effects of the $\mathrm{pH}$ on the fluorescent derivatization of KA with HRP. The conditions are same as in Fig. 1, except for the $\mathrm{pH}$ of a 1/15 M phosphate buffer solution.

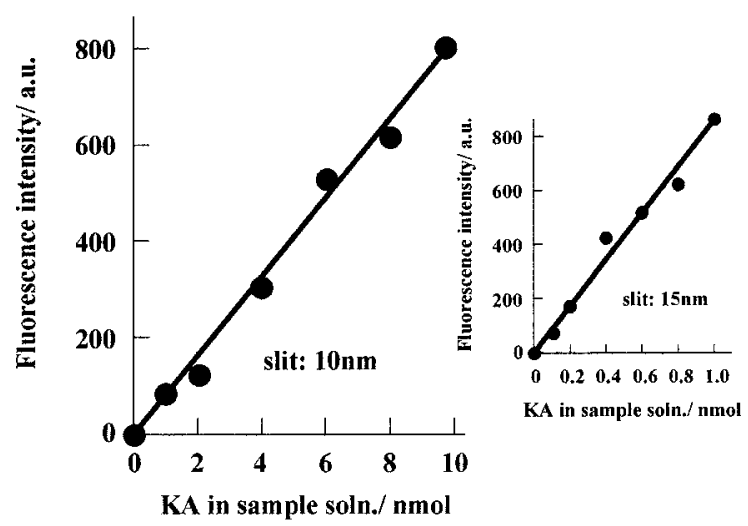

Fig. 3 Calibration curves in the range of 1.0 to $10 \mu \mathrm{mol}$ of KA and 0.1 to $1.0 \mu \mathrm{mol}$ of $\mathrm{KA}$ in a $1.0 \mathrm{~mL}$ sample solution, respectively.

also linear in the range between 0.1 and $1.0 \mathrm{nmol}$ of KA in a 1.0 $\mathrm{mL}$ sample solution. Accordingly, the HRP method is applicable to the fluorometric determination of trace amounts of KA. Although the sensitivity of the present method does not always correspond to that of the fluorometric methods employed by Watanabe et al., ${ }^{14,15}$ it will be satisfactory for the determination of trace amounts of KA in vital fluids in conjunction with HPLC.

\section{Effect of foreign substances}

Interference in the HRP method was investigated in the presence of various foreign substances and ions. Since HRP is originally an enzyme associated with oxidation-reduction reaction systems, some reducing and oxidizing substances may affect the fluorescent derivatization of KA with HRP in the presence of $\mathrm{H}_{2} \mathrm{O}_{2}$. Accordingly, as shown in Table 3, reducing substances, such as ascorbate and iodide ions, showed severe interference. In the case of a sample solution containing human serum albumin (HSA), the fluorescence spectrum derived from HSA was predominantly observed, because HSA is fluorescent. The removal of protein from a vital sample containing a fluorescent protein should be necessary for the determination of trace amounts of KA. Other substances and ions showed almost no interference. 
Table 3 Effect of foreign substances on the fluorescent derivatization of KA with $\mathrm{HRP}$ in the presence of $\mathrm{H}_{2} \mathrm{O}_{2}$ without exposure to light (KA added: $1.0 \mathrm{nmol}$ )

\begin{tabular}{lcclcc}
\hline \multicolumn{1}{c}{ Substrate } & $\begin{array}{c}\text { Added/ } \\
\text { nmol }\end{array}$ & $\begin{array}{c}\text { Error, } \\
\%\end{array}$ & Substrate & $\begin{array}{c}\text { Added/ } \\
\text { nmol }\end{array}$ & $\begin{array}{c}\text { Error, } \\
\%\end{array}$ \\
\hline Heparin & 17.3 (I.U.) & +1.8 & $\mathrm{~K}^{+}$ & 10 & +7.7 \\
Glycine & 10 & -2.8 & $\mathrm{Ca}^{2+}$ & 10 & +7.0 \\
Albumin (HSA) & $20 \mathrm{mg}$ & $-{ }^{\mathrm{a}}$ & $\mathrm{Fe}^{3+}$ & 10 & -3.9 \\
Ascorbic acid & 10 & -38.3 & $\mathrm{CO}_{3}^{2-}$ & 10 & +4.1 \\
Citric acid & 10 & -1.4 & $\mathrm{Br}^{-}$ & 10 & -5.8 \\
Acetic acid & 10 & +3.2 & $\mathrm{I}^{-}$ & 10 & -44.6 \\
$\mathrm{NH}_{4}{ }^{+}$ & 10 & +1.0 & $\mathrm{~F}^{-}$ & 10 & +4.3 \\
\hline
\end{tabular}

a. A fluorescence spectrum derived from HSA was observed.

Application to the determination of $K A$ in sera

The HRP method was applied to the determination of KA spiked in control serum I and II. Because the HRP method was affected by HSA, as shown in Table 3, the sample solution after the removal of serum proteins in the control sera was applied to the determination of KA. KA was added to each control serum I and II prior to the removal of serum proteins, and each solution was used as a sample solution for the HRP method. The recoveries of KA added to each control serum were $92.7 \pm$ $0.8(n=3)$ and $90.7 \pm 0.7(n=3)$ for control serum I and II, respectively. The results were satisfactory for both control serum I and II. Price et al. have reported that the amounts of $\mathrm{KA}$ in urine of health adults were $13.3 \pm 4.0 \mu \mathrm{mol} \mathrm{day}{ }^{-1}$ in males and $13.2 \pm 1.8 \mu \mathrm{mol} \mathrm{day}^{-1}$ in females. ${ }^{20}$ Accordingly, the HRP method may be applied to the determination of KA in human urine sample, although the pretreatment, such as the concentration of urine sample or the extraction of KA from urine sample, should be required.

\section{Conclusions}

Non-fluorescent KA was easily converted into a fluorescent compound by the catalytic activity of HRP in the presence of $\mathrm{H}_{2} \mathrm{O}_{2}$, even without exposure to light. The HRP method using this fluorescent derivatization of KA was useful for the fluorometric determination of trace amounts of KA. This is the first example of the determination of $\mathrm{KA}$ using the catalytic activity of HRP in the presence of $\mathrm{H}_{2} \mathrm{O}_{2}$. Moreover, this HRP method was also useful for the fluorometric determination of trace amounts of KA in vital fluids, such as plasma.

\section{References}

1. M. Kanai, H. Okabe, M. Sekiguchi, S. Nomoto, M. Kameko, M. Isobe, M. Tozuka, H. Hidaka, M. Oguchi, and S. Kawa, "Rinsyo-Kensaho-Teiyo (in Japanese)", ed. I. Kanai and M. Kanai, 1998, Chap. 6, Kinbara Press, Tokyo.

2. M. J. Navas, A. M. Jimenez, and G. Galan, Atmos. Environ., 1999, 33, 2279.

3. T. Nakayama, Gekkan Fudo Kemikaru, 1989, 70.

4. A. Kosaka, Kensa to Gijutsu, 1981, 9, 867.

5. K. Zaitsu and Y. Ohkura, Anal. Biochem., 1980, 109, 109.

6. G. G. Guilbault, P. Jr. Brignac, and M. Zimmer, Anal. Chem., 1968, 40, 190.

7. Y. Kotake and E. Murakami, Sougou Rinshyo, 1968, 17, 495.

8. M. Hattori, Y. Kotake, and Y. Kotake, Acta Vitaminol. Enzymol., 1984, 6, 221.

9. S. Erhardt, K. Blennow, C. Nordin, E. Skogh, L. H. Lindstrom, and G. Engberg, Neurosci. Lett., 2001, 313, 96.

10. J. Parada-Turska, W. Rzeski, W. Zgrajka, M. Majdan, M. Kandefer-Szerszen, and W. Turski, Rheumat. Intern., 2006, 26, 422 .

11. M. Bizzarri, A. Catizone, M. Pompei, L. Chiappini, L. Curini, and A. Lagana, Biomed. Chromatogr., 1990, 4, 24.

12. A. Amirkhani, E. Heldin, K. E. Karin, and J. Bergquist, J. Chromatogr., B, 2002, 780, 381.

13. D. Coppini, Acta Vitaminol. Enzymol., 1975, 29, 35.

14. F. Iinuma, M. Tabara, K. Yashiro, and M. Watanabe, Bunseki Kagaku, 1985, 34, 483.

15. K. Mawatari, F. Iinuma, and M. Watanabe, Anal. Sci., 1988, 4, 195.

16. S. Mitsuhashi, T. Fukushima, J. Kawai, M. Tomiya, T. Santa, K. Imai, and T. Toyo'oka, Anal. Chim. Acta, 2006, $562,36$.

17. K. Mawatari, F. Iinuma, and M. Watanabe, Anal. Sci., 1991, 7, 783.

18. G. G. Guilbault, P. J. Brignac, and M. Juneau, Anal. Chem., 1968, 40, 1256.

19. F. Kusu, T. Tsuneta, and K. Takamura, Bunseki Kagaku, 1990, 39, 115.

20. J. M. Price, R. R. Brown, and N. Yess, "Advances in Metabolic Disorders", ed. R. Levine and R. Luft, 1965, Academic Press, New York, 159. 